\title{
Psychopathic personality in young people
}

\section{Mairead Dolan}

\begin{abstract}
This article is an overview of developments in psychopathy and their application to children and adolescents. A key question is whether or not psychopathy is stable throughout the lifespan. Some characteristics indicate phenotypic similarities with adult psychopathy, and current instruments appear to be measuring similar constructs across the age ranges. Although the literature on developmental aspects of psychopathy in young people is limited, a number of instruments have been designed to measure the construct. These tools appear to have reasonable construct, concurrent and predictive validity, but we cannot yet recommend their routine use in clinical practice or in the criminal justice system, given the limited evidence base on their predictive validity. At best, they should be viewed as a means of subtyping potentially high-risk groups with a view to treatment planning.
\end{abstract}

This article continues the series entitled 'Lifespan psychiatry', which considers the developmental psychiatry of adulthood. Previous articles looked at attention-deficit hyperactivity disorder (Zwi \& York, 2004; Invited commentaries: Asherson, 2004 and Coghill, 2004) and Asperger syndrome (Berney, 2004).

Psychopathy is a personality disorder characterised by a constellation of interpersonal, affective and behavioural characteristics (Hare, 1998). The early literature suggested that it was a uni-dimensional phenomenon, but subsequent studies revealed that measures of psychopathy had at least a two-factor structure, comprising an interpersonal/affective element (factor 1) and a social deviance component (factor 2). More recently, a three-factor structure has been proposed (Cooke \& Michie, 2001), which includes:

- an arrogant, deceitful interpersonal style, involving dishonesty, manipulation, grandiosity and glibness;

- defective emotional experience, involving lack of remorse, poor empathy, shallow emotions and a lack of responsibility for one's own actions;

- behavioural manifestations of impulsiveness, irresponsibility and sensation-seeking.

Conduct disorder, antisocial personality disorder and psychopathy are often seen as developmental disorders that span the life course and the terms are sometimes used interchangeably. There are, however, significant differences between them and their associated correlates. Whereas conduct disorder and antisocial personality disorder primarily focus on behavioural problems, psychopathy, as described by Hare (1991), emphasises deficits in affective and interpersonal functioning. Psychopathy is seen as a higher-order construct, which can now be reliably be assessed in adults using the Psychopathy Checklist - Revised (PCL-R; Hare, 1991). A score of $>30$ on the PCL-R indicates prototypical psychopathy.

The estimated prevalence of adult psychopathy in the general population is $1 \%$, rising to between $15 \%$ and $25 \%$ in incarcerated groups. The notion that individuals identified as PCL-R 'psychopaths' are different from people with a diagnosis of antisocial personality disorder comes from research showing that there are high rates (50-80\%) of antisocial personality disorder in prison populations, but only $20 \%$ of these meet Hare's criteria for psychopathy (Hare, 1998).

\section{Aetiology of psychopathy}

The biological and environmental factors responsible for the development and maintenance of antisocial behaviour and psychopathy are not well understood. Studies in children and adolescents (Forth \& Burke, 1998) indicate that several family background variables (e.g. parental rejection, inconsistent discipline, abuse) are associated with the development of conduct disorder and psychopathy. However, an independent literature also suggests that children with conduct disorder,

Mairead Dolan is a reader in forensic psychiatry at the University of Manchester (The Edenfield Centre, Bolton, Salford \& Trafford Mental Health NHS Trust, Prestwich, Manchester M25 3BL, UK. E-mail: mdolan@edenfield.bstmht.nhs.uk). Her research interests include antisocial and psychopathic personality disorders. 
particularly those with a history of repeated violent behaviour, exhibit neuropsychological deficits (Moffitt \& Henry, 1991) and have reduced levels of arousal, including reduced plasma cortisol levels (Raine, 1993; McBurnett \& Lahey, 1994). These findings suggest a role for neurobiological factors, particularly executive (prefrontal) and temporolimbic (amygdala) dysfunction, in the aetiology of conduct disorder and psychopathy.

\section{The prefrontal cortex and behaviour}

There are a number of theories relating to the neurological basis of antisocial behaviour and psychopathy. Of those focusing on the prefrontal cortex, the most prominent are the somatic marker hypothesis (Damasio, 1994) and the response modulation deficit hypothesis (for a review see Newman, 1998).

The somatic marker hypothesis suggests that damage to the ventromedial cortex results in a failure of the somatosensory structures to mark experiences as good or bad, and consequently there is no mechanism for learning to avoid aversive situations. This model receives some support from studies of acquired psychopathy, where subjects show an attenuated autonomic response to aversive social stimuli.

The response modulation deficit hypothesis, which also focuses on the ventromedial prefrontal cortex, accounts for the risk-taking behaviour and failure to learn from experience seen in criminals with psychopathic personality performing laboratory-based tasks of passive-avoidance learning. Some support for the response modulation deficit hypothesis comes from studies revealing that children with marked callous and unemotional traits show an insensitivity to punishment cues on a gambling task (Frick, 1998).

\section{The amygdala and affect}

There are also two main theories relating to the affective characteristics of psychopathy: the punishment/low-fear theory (Lykken, 1995) and the violence inhibition mechanism deficit hypothesis (Blair, 1995). Both models suggest a crucial role for the amygdala as the seat of dysfunction in psychopathic individuals. The low-fear model stresses the aspects of psychopathy related to sensation-seeking and insensitivity to punishment (Lykken, 1995; Patrick, 1994), whereas the violence inhibition mechanism model accounts for the specific failure of basic emotions (e.g. fear) to result in autonomic arousal and the inhibition of ongoing behaviour in individuals with psychopathic personality.

To date, few of these theories have been extensively tested in child and adolescent samples. However, some support for the violence inhibition mechanism model has emerged in studies showing a selective impairment in the processing of sad and fearful faces in children with psychopathic tendencies (Blair et al, 2001).

\section{The relationship between callous-unemotional traits and conduct disorder}

Frick (1998) outlined a basic framework for conceptualising the relationship between what he termed callous-unemotional traits and conduct problems in children. In this model, callousunemotional traits develop as part of a unique temperamental style, low behavioural inhibition, which makes the child poorly responsive to socialisation. Kochanska (1993) suggested that behavioural inhibition is critical in the development of conscience in young children and reported that low-fear children did not respond to the type of socialisation (gentle, non-power, assertive discipline) that led to conscience development in more fearful children. Subsequent studies in children with conduct disorder indicated that the style parents use to socialise their child has less impact on the development of conduct problems in children with callous-unemotional traits, suggesting that genetic or neurodevelopmental factors make a more significant contribution in children who are notably callous.

\section{Psychopathy in children and adolescents}

The existence and assessment of psychopathy in children and adolescents is a contentious issue (Edens et al, 2001; Hart et al, 2002; Seagrave \& Grisso, 2002). Key concerns centre on the reliability and validity of current assessment tools, the developmental appropriateness of these measures, how closely the construct mimics that in adulthood and the potentially negative impact of attaching a label of psychopathy to those who have not yet reached maturity (Box 1).

Frick (2002) argues that psychopathy presents no more of a challenge than any other measure of psychopathology in children and adolescents, and suggests that psychopathy assessment in juveniles may be a means of early detection and intervention in high-risk groups. 
Box 1 Key concerns about psychopathy assessment in juveniles

- How early can psychopathic traits be reliability detected?

- Are there developmentally appropriate measures of psychopathy for use in children and adolescents?

- What is the prevalence of psychopathy in childhood and adolescence?

- Does its presentation mimic that in adulthood and has it construct and concurrent validity?

- What is the developmental stability of psychopathy over the lifespan?

- What is the predictive validity of current childhood and adolescent measures of psychopathy?

- What is the impact of attributing a label of psychopathy in childhood and adolescence?

\section{Can psychopathic traits be reliably detected?}

The notion that personality disorder and psychopathy can be diagnosed in childhood and adolescence has provoked debate in the literature. Some (e.g. Frick, 2002; Lynam, 2002) argue that, theoretically, personality traits are relatively stable across adolescence into adulthood and that there remarkable similarities between the literature on psychopathy in adults and that emerging on children and adolescents. Others (e.g. Seagrave \& Grisso, 2002) suggest that psychopathy as a construct has a high false-positive rate in adolescence, as this is period of considerable developmental change. Cleckley (1976) also noted that certain transient developmental behaviours and attributes that arise in childhood and adolescence resemble psychopathic traits but attenuate with normal development. For example, adolescents are known to be more impulsive and have less empathic understanding than adults, which might result in higher scores on these items on current psychopathy measures.

To date, there have been no studies looking at the stability of psychopathic traits across the younger age range, and such work is needed. In the adult literature it has been noted that the behavioural items are less stable than the interpersonal/affective items. This has led to recent proposals that psychopathy should focus primarily on callous-unemotional and affective traits, as these are the core components that characterise it and they have been found to be relatively stable, remaining apparent past the age of 40 , when the more impulsive, aggressive and criminal behaviours tend to decline or 'burn out'.

\section{Are there developmentally appropriate} measures of psychopathy?

Some researchers have modified adult measures of psychopathy to take account of developmental and social/peer-group influences in an attempt to deal with the above concerns. For example, Forth et al (2004) modified PCL-R items for adolescents. Others have developed new measures with items that may be more applicable to children and adolescents (e.g. Lynam, 1997; Frick, 1998). But although there are now measures of psychopathy in childhood and adolescence, four of which are listed in Box 2, there is a distinct lack of data on their temporal stability.

\section{What are the psychometric properties of current psychopathy measures?}

To date, there is relatively little literature on the psychometric properties of measures of psychopathy designed for use with children and adolescents. Preliminary data (see below) show that the external correlates of psychopathy in young people are similar to those seen in affected adults, suggesting some phenotypic similarities. For the Psychopathy Checklist: Youth Version (PCL-YV) (Boxes 2 \& 3) there is evidence of adequate internal consistency and interrater reliability for total scores (Forth \& Burke, 1998). However, relatively little is known about the factor structure of this instrument across settings, genders and ethnic groups and there have been no studies of its test-retest reliability.

The Psychopathy Screening Device (PSD) was initially reported to have a two-factor structure (Frick et al, 1994). The first was labelled the impulsive-conduct problem scale, and it roughly corresponded to the social deviance (factor 2) scale of the adult PCL-R. The second was the callousunemotional scale, which roughly corresponded to the interpersonal/affective (factor 1) scale of the PCL-R. As yet, there are no specific cut-off scores for the PSD, so a diagnosis of prototypical psychopathy cannot be made with this instrument.

Data on the psychometric properties of the Childhood Psychopathy Scale (CPS) is limited and Lynam (1997) generally uses the total rather than sub-scale scores in data analyses.

The Youth Psychopathic Traits Inventory (YPI) has been shown to have acceptable internal consistency. Factor analyses have revealed a threefactor structure similar to that reported for adults (Cooke \& Michie, 2001).

To date, there is relatively little information on whether the self-report (the YPI) and parent/teacherrated (the PSD and CPS) measures are susceptible to response bias or positive impression management 


\section{Box 2 Current intruments for assessing psychopathy in children and adolescents}

Psychopathy Checklist: Youth Version (PCL-YV; Forth et al (2004)

A clinician-rated scale for use with adolescents aged 13-18 years. The PCL-YV, like the adult PCL-R from which it was derived, has a two-factor structure, one reflecting the interpersonal and affective aspects of personality function and the other reflecting the chronic antisocial lifestyle.

Psychopathy Screening Device (PSD; Frick, 1998)

(Also becoming know as the Antisocial Process Screening Device.) This 20-item measure was designed to measure psychopathy in children aged 6-12 years. It is completed by teachers or parents, rather than by self-report or interview with the young people themselves, because of concerns about the validity of children's accounts of their own emotional and behavioural difficulties (Kamphaus \& Frick, 1996).

Childhood Psychopathy Scale (CPS; Lynam, 1997)

A parent/teacher-rated scale designed to assess psychopathy in late childhood and early adolescence. The 13-item CPS was derived from the Pittsburgh Youth study on 12-13-year-old boys and has a set of items that are similar to the behavioural items on the adult PCL-R.

Youth Psychopathic Traits Inventory (YPI; Andershed et al, 2002)

A self-report, 50-item scale designed for young people of 12 years or older. Its sub-scales include dishonest charm, grandiosity, lying, manipulation, callousness, unemotionality, remorselessness, irresponsibility and thrill-seeking. Respondents are asked to rate the degree to which individual statements or items apply to them. To avoid response distortion and social desirability effects, items are framed as potentially positive attributes. For example, for dishonest charm a sample item is 'When I need to, I use my smile and my charm to use others'. The instrument primarily focuses on the core personality traits of the psychopathic personality constellation, rather than on the behavioural traits associated with it.

(social desirability), and none of these instruments has a validity scale to check response distortion.

\section{Does the presentation mimic that in adults?}

Several studies have shown parallels between patterns of offending behaviour in both adults and adolescents identified as psychopaths. Delinquent offenders with pronounced psychopathic traits have an earlier onset of offending (Brandt et al, 1997; Forth \& Burke, 1998), commit more crimes, and reoffend more often (Forth \& Burke, 1998; Myers, 1995) and more violently (Brandt et al, 1997; Spain et al, 2004) than non-psychopathic criminal youth. Psychopathy scores have also been found to correlate significantly with the severity of conduct problems, antisocial behaviour and delinquency in adolescents (Forth \& Burke, 1998). In children, the CPS score correlates significantly with measures of impulsivity and adds incremental validity to the prediction of delinquency at ages 12 and 13 years. The PSD impulsive-conduct problem scale has been shown to correlate with traditional measures of conduct disorder (Frick et al, 1994). Furthermore, Christian et al (1997) have also demonstrated that children with callous-unemotional traits engage in more persistent antisocial behaviour. In addition, they exhibit insensitivity to punishment cues irrespective of whether or not they have conduct problems (O'Brien \& Frick, 1996). These findings appear to fit with similar studies examining emotional and information-processing deficits in both adolescents and adults identified as psychopaths and assessed using similar measures (Hare, 1998; Newman, 1998). Studies examining the validity of the YPI also indicate high correlations with early behavioural problems, poor behavioural control and hyperactivity-impulsivity attention difficulties (Andershed et al, 2002). However, this measure has not yet been compared with alternative measures of juvenile psychopathy.

\section{Prevalence of psychopathy in forensic samples}

At present, there are no data on the prevalence of psychopathy in the juvenile general population. Using a PCL-YV cut-off score of $>30$ in a population of adolescents already involved with criminal or psychiatric services, Forth \& Burke (1998) found rates of psychopathy of $3.5 \%$ in young people in community care, $12 \%$ in those on probation and $28.3 \%$ in those incarcerated. Brandt et al (1997) reported a prevalence of $37 \%$ in incarcerated youths, using a PCL-YV cut-off score of $>28$. As there are no recommended cut-off scores for diagnoses of psychopathy using the CPS, PSD or YPI, prevalence rates using these measures have not been reported. 


\section{Box 3 Item content of the Hare Psychopathy Checklist: Youth Version (after Forth et al, 2004)}

1 Impression management Conforms with notions of social desirability, presents him- or herself in a good light, is superficially charming

2 Grandiose sense of self-worth Is dominating, opinionated, has an inflated view of own ability

3 Stimulation-seeking Needs novelty, excitement, is prone to boredom and risk-taking behaviours

4 Pathological lying Exhibits pervasive lying, lies readily, easily and obviously

5 Manipulation for personal gain Is deceitful, manipulates, engages in dishonest or fraudulent schemes that can result in criminal activity

6 Lack of remorse Has no guilt, lacks concern about the impact of his or her actions on others; justifies and rationalise their abuse of others

7 Shallow affect Has only superficial bonds with others, feigns emotion

8 Callous or lacking empathy Has a profound lack of empathy, views others as objects, has no appreciation of the needs or feelings of others

9 Parasitic orientation Exploits others, lives at the expense of friends and family, gets others to do his or her schoolwork using threats

10 Poor anger control Is hotheaded, easily offended and reacts aggressively, is easily provoked to violence

11 Impersonal sexual behaviour Has multiple casual sexual encounters, indiscriminate sexual relationships, uses coercion and threats

12 Early behavioural problems Lying, thieving, fire-setting before 10 years of age

13 Lacks goals Has no interest or understanding of the need for education, lives day-to-day, has unrealistic aspirations for the future

14 Impulsivity Acts out frequently, quits school, leaves home on a whim, acts on the spur of the moment, never considers the consequences of impulsive acts

15 Irresponsibility Habitually fails to honour obligations or debts, shows reckless behaviour in a variety of settings, including school and home

16 Failure to accept responsibility Blames other for his or her problems, claims that he or she was 'set $\mathrm{up}^{\prime}$, is unable and unwilling to accept personal responsibility for their actions

17 Unstable interpersonal relationships Has turbulent extrafamilial relationships, lacks commitment and loyalty

18 Serious criminal behaviour Has multiple charges of convictions for criminal activity

19 Serious violations of conditional release Has two or more escapes from security or breaches of probation

20 Criminal versatility Engages in at least six different categories of offending behaviour

Overall, there seems to be some evidence that the base rate of psychopathy in adolescence is higher (Brandt et al, 1997; Forth \& Burke, 1998) than that reported in adult samples (Hare, 1991, 1998). This has prompted questions about the validity of current 'age-appropriate' measures and the stability of psychopathy over the lifespan (Edens et al, 2001; Seagrave \& Grisso, 2002). If the construct of psychopathy were valid and stable then one would expect similar prevalence rates across the lifespan. It is possible that the inflated scores on adolescent psychopathy measures are due to higher ratings on items relating to impulsivity and irresponsibility in younger samples.

\section{Comorbidity}

The only published studies looking at comorbidity of psychopathy with other psychiatric disorders in adolescent populations have focused on groups with substance misuse disorders, where the prevalence of comorbid psychopathy is high (e.g. Brandt et al, 1997; Mailloux et al, 1997). Although the social deviance component of psychopathy shows item overlap with the criteria for DSM-IV disruptive behaviour disorders and attention-deficit hyperactivity disorder (ADHD), no study has specifically addressed the nature of the relationship between psychopathic traits and these disorders in younger cohorts. This is likely to be an important area for further research, as deficits in executive function have been reported in individuals with these disorders as well as in people who score highly on the impulsive-aggressive domains of the psychopathy construct.

The callous-unemotional and interpersonal aspects of psychopathy share some features with the pervasive developmental disorders. To date, 
there have been no studies in forensic cohorts to explore the similarities and differences between these disorders or the level of comorbidity between them, despite evidence that autistic-spectrum disorders are prevalent in criminal samples (Soderstrom et al, 2004). As amygdala dysfunction has been implicated in the pathogenesis of both autism and psychopathy and both disorders are viewed as involving impairments in social functioning there is a need to clarify how these disorders can be differentiated so that appropriate treatment programmes can be developed.

\section{Outcome}

In the adult literature there is some evidence that psychopathy is a significant negative moderator of treatment outcome (Losel, 1998). To date, two studies have looked at the relationship between psychopathy and treatment outcome in adolescents, but none has considered this in children. Rogers et al (1997) found modest correlations between psychopathy scores and ratings of non-compliance with treatment in 81 adolescent in-patients. O'Neill et al (2003) also reported that psychopathy score was negatively correlated with attendance rates, quality of participation and clinical improvement in adolescents in a substance misuse treatment programme. These findings suggest that psychopathy may be an important moderator of treatment outcome in adolescents as in adults, and specialised programmes may be needed for young people with psychopathic traits. Forth \& Burke (1998) also point out that juveniles identified as psychopathic may be more 'malleable' and benefit more from treatment than their older counterparts

\section{Psychopathy as a predictor of violence?}

Psychopathy has been shown to be a robust predictor of future institutional and post-discharge violence in adults (Salekin et al, 1996), and the results of studies in adolescent samples largely concur with this finding. Psychopathy scores in adolescents have been found to be associated with both the frequency of violent recidivism (Forth et al, 1990) and a shorter time to violent recidivism (Brandt et al, 1997). Studies of institutional violence indicate moderately strong correlations between psychopathy score and verbal and physical aggression (Edens et al, 2001; Spain et al, 2004).

None of the adolescent studies has examined which (if any) of the callous-unemotional or behavioural factors of the psychopathy subscales contribute most to predictive accuracy. As yet, there have been no risk prediction studies at all in children with psychopathic traits.

\section{Are the neurocognitive markers similar in young people and adults?}

From a neurocognitive perspective there is some evidence that children and adolescents with psychopathy display deficits on experimental tasks assessing impulse control and empathy (Blair, 1999; Barry et al, 2000) similar to those seen in adults (Hare, 1998; Newman, 1998). In children with emotional and behavioural problems, PSD scores predicted electrodermal responses to distress cues and threatening stimuli (Blair, 1999) as well as differences in moral reasoning (Blair, 1997). This work lends support to Blair's violence inhibition mechanism model of psychopathy.

\section{Use of psychopathy assessments in the criminal justice system}

A number of researchers and clinicians in the field have advocated caution in the use of current psychopathy assessment tools as a means of informing the criminal justice system on sentence planning for young people, particularly in light of the fact that in adults a diagnosis of psychopathy can result in more severe sentences. Instruments developed for assessing psychopathy in child and adolescent populations require further validation in a variety of populations and settings before they can be fully accepted. Only then can they be used with confidence in the criminal justice system.

\section{Conclusions}

The assessment of psychopathy in children and adolescents is a very important area of research and it is still in its infancy. There seems to be reasonable evidence that juvenile psychopathy shows similar correlates (e.g. aggression, neurocognitive deficits, substance misuse) to adult psychopathy. Our knowledge about the nature, stability and consequences of juvenile psychopathy, however, is still very limited. There have been no published longitudinal studies of the stability of psychopathy as assessed by any of the current measures and it remains unclear to what degree the antisocial behavioural items that contribute to the psychopathy label change over time, given what we know about adolescent-limited antisocial behaviours. The limited data on the psychometric properties of current instruments, particularly information on recommended or specific cut-off scores for prototypical psychopathy, suggest that it is premature to assign this label to younger cohorts. For this reason many researchers in this field refer to juveniles with 
'psychopathic characteristics' rather than using the term 'psychopathy'.

However, these instruments do include items we know to be associated with high-risk behaviours, and they can inform clinical assessments of risk and treatment planning.

At present, there is no general agreement on whether or not psychopathy exists in childhood and adolescence. A consensus is likely to be reached only when we have longitudinal studies demonstrating the stability of psychopathic traits over the lifespan and evidence that the same aetiological factors contribute to this disorder at all ages. As there is significant overlap between the behavioural aspects of juvenile psychopathy and ADHD and between the callous-unemotional dimension of psychopathy and autistic-spectrum disorders, future work needs to disentangle these constructs from a phenomenological and aetiological perspective.

As yet, there are few treatment outcome studies in juveniles with psychopathic traits, although the limited data suggest that these traits might be a moderator of outcome. Most clinicians view youth psychopathy as a potentially treatable disorder, and there is some evidence that identification of psychopathic traits in young people has a number of benefits, which include:

- identifying high-risk offenders;

- reducing misclassifications that have negative ramifications for children and adolescents;

- improving and optimising treatment planning for young people with psychopathic traits, who may require more intensive and riskfocused therapeutic approaches.

\section{References}

Andershed, H., Kerr, M., Stattin, H., et al (2002) Psychopathic traits in non-referred youths: a new assessment tool. In Psychopaths - Current International Perspectives (eds Blaauw, E. \& Sheridan, L.). The Hague: Elsevier.

Asherson, P. P. (2004) Bridging the service divide. Invited commentary on Attention-deficit hyperactivity disorder in adults. Advances in Psychiatric Treatment, 10, 257-259.

Barry C. T., Frick P. J., DeShazo T. M., et al (2000) The importance of callous-unemotional traits for extending the concept of psychopathy to children. Journal of Abnormal Psychology, 109, 335-340.

Berney, T. (2004) Asperger syndrome from childhood into adulthood. Advances in Psychiatric Treatment, 10, 341-351.

Blair, R. J. R. (1995) A cognitive developmental approach to morality: investigating the psychopath. Cognition, 57, $1-29$.

Blair, R. J. R. (1997) Moral reasoning and the child with psychopathic tendencies. Personality and Individual Differences, 22, 731-739.

Blair, R. J. R. (1999) Responsiveness to distress cues in the child with psychopathic tendencies. Personality and Individual Differences, 27, 135-145.

Blair, R. J. R., Colledge, E., Murray, L, et al (2001) A selective impairment in the processing of sad and fearful expressions in children with psychopathic tendencies? Journal of Abnormal Child Psychology, 29, 491-498.
Brandt, J. R., Kennedy, W. A., Patrick, C. J., et al (1997) Assessment of psychopathy in a population of incarcerated adolescent offenders. Psychological Assessment, 9, 429-435.

Christian, R. E., Frick, P. J., Hill, N., et al (1997) Psychopathy and conduct problems in children: II. Sub typing children with conduct problems based on their interpersonal and affective style. Journal of the American Academy of Child and Adolescent Psychiatry, 36, 233-241.

Cleckley, H. (1976) The Mask of Sanity (5th edn). St Louis, MI: Mosby.

Coghill, D. (2004) Understudied and underrecognised Invited commentary on Attention-deficit hyperactivity disorder in adults. Advances in Psychiatric Treatment, 10, 338-340.

Cooke D. J. \& Michie C. (2001) Refining the construct of psychopathy: towards a hierarchical model. Psychological Assessment, 13, 171-188.

Damasio, A. (1994) Descartes' Error: Emotion, Reason, and the Human Brian. New York: Putnam \& Sons

Edens J. F., Skeem, J. L., Cruise, K. R., et al (2001) Assessment of 'juvenile psychopathy' and its association with violence. A critical review. Behavioral Sciences and the Law, 19, 53-58.

Forth, A. E. \& Burke H. C. (1998) Psychopathy in adolescence: assessment, violence and developmental precursors. In Psychopathy: Theory, Research and Implications for Society (eds D. Cooke, A. Forth \& R. Hare), pp. 205-230. Dordrecht: Kluwer.

Forth, A. E., Hart, S. D., \& Hare, R. D. (1990) Assessment of psychopathy in male young offenders. Psychological Assessment: A Journal of Consulting and Clinical Psychology, 2, 342-344.

Forth, A. E., Kosson, D. S. \& Hare R. D. (2004) The Hare Psychopathy Checklist: Youth Version (PCL-YV) - Rating Guide. Toronto, Ontario: Multi Health Systems.

Frick, P. J. (1998) Callous-unemotional traits and conduct problems: applying the two-factor model of psychopathy to children. In Psychopathy: Theory, Research and Implications for Society (eds D. Cooke, A. Forth \& R. Hare), pp. 161189. Dordrecht: Kluwer.

Frick, P. J. (2002) Juvenile psychopathy from a developmental perspective: Implications for construct development and use in forensic assessments. Law and Human Behaviour, 26, 247-253.

Frick, P. J., O'Brien, B. S., Wootton, J. M., et al (1994) Psychopathy and conduct disorders in children. Journal of Abnormal Psychology, 103, 700-707.

Hare, R. D. (1991) The Hare Psychopathy Checklist - Revised. Toronto: Multi Health Systems.

Hare, R. D (1998) Psychopathy, affect and behaviour. In Psychopathy: Theory, Research and Implications for Society (eds D. Cooke, A. Forth \& R. Hare), pp. 105--139. Dordrecht: Kluwer

Hart, S. D., Watts, K. \& Vincent, G. M. (2002) Commentary on Seagrave and Grisso: Impressions of the state of the art. Law and Human Behavior, 26, 241-245.

Kamphaus, R. W. \& Frick, P. J. (1996) Clinical Assessment of Child and Adolescent Personality and Behavior. Boston, MA Allyn \& Bacon.

Kochanska, G. (1993) Towards a synthesis of parental socialisation and child temperament in early development of conscience. Child Development, 64, 228-240.

Kosson, D., Cyterski, T., Steuerwald, B., et al (2001) The reliability and validity of the Psychopathy Checklist: Youth Version (PCL: VY) in non-incarcerated adolescent males. Psychological Assessment, 14, 97-109.

Losel F (1998) Treatment and management of psychopaths. In Psychopathy: Theory, Research, and Implications for Society (eds D. J. Cooke, A. E. Forth, \& R. D. Hare), pp. 303-355. Dordrecht: Kluwer.

Lykken, D. T (1995) The Antisocial Personalities. Hillsdale. NJ: Lawrence Erlbaum.

Lynam D. R. (1997) Pursuing the psychopath: capturing the fledgling psychopath in a nomological net. Journal of Abnormal Psychology, 106, 425-438.

Lynam D. R. (2002) Fledgling psychopathy: a view from personality theory. Law and Human Behavior, 26, 255-259. 
Mailloux, D. L., Forth, A. E. \& Kroner, D. G. (1997) Psychopathy and substance use in adolescent male offenders. Psychological Reports, 80, 529-530.

McBurnett, K. \& Lahey, B. B. (1994) Psychophysiological and neuroendocrine correlates of conduct disorder and antisocial behaviour in children and adolescents. In Progress in Experimental Personality \& Psychopathology Research (eds D. C Fowles, P. Sutker \& S. Goodman), pp.199-231. New York: Springer.

Moffitt, T. E. \& Henry, B. (1991) Neuropsychological studies of juvenile delinquency and violence: a review. In Neuropsychology of Aggression (ed. J. S. Milner), pp. 131140. Norwell: Kluwer Academic.

Myers, W. C., Burket, R. C. \& Harris, H. E. (1995) Adolescent psychopathy in relation to delinquent behaviours, conduct disorder, and personality disorder. Journal of Forensic Sciences, 40, 436-440.

Newman, J. P. (1998) Psychopathic behaviour: An information processing perspective. In Psychopathy: Theory, Research, and Implications for Society (eds D. J. Cooke, A. E. Forth \& R. D. Hare), pp. 81-104. Dordrecht: Kluwer.

O'Brien, B. S. \& Frick, P. J. (1996) Reward dominance: Associations with anxiety conduct problems and psychopathy in children. Journal of Abnormal Child Psychology, 24, 223-240.

O'Neill, M., Lidz, V. \& Heilbrun K. (2003) Adolescents with psychopathic characteristics in a substance-abusing cohort. Treatment process and outcomes. Law and Human Behavior, 27, 299-313.

Patrick, C. J. (1994) Emotion and psychopathy: startling new insights. Psychophysiology, 31, 319-330.

Raine, A. (1993) The Psychopathology of Crime: Criminal Behavior as a Clinical Ddisorder. San Diego, CA: Academic Press.

Rogers, R., Johansen, J., Chang, J. J., et al (1997) Predictors of adolescent psychopathy: oppositional and conductdisordered symptoms. Journal of the American Academy of Psychiatry and the Law, 25, 261-271.

Salekin, R., Rogers, R. \& Sewell, K. (1996) A review and meta-analysis of the Psychopathy Checklist and Psychopathy Checklist - Revised: predictive validity of dangerousness. Clinical Psychology: Science and Practice, 3, 203-215

Seagrave, D. \& Grisso, T. (2002) Adolescent development and the measurement of juvenile psychopathy. Law and Human Behavior, 26, 219-239.

Soderstrom, H., Sjodin, A.-K. \& Carlstedt, A. F. (2004) Adult psychopathic personality with childhood-onset hyperactivity and conduct disorder: a central problem constellation in forensic psychiatry. Psychiatry Research, 121, 271-280.

Spain, S. E., Douglas, K. S., Poythress, N. G., et al (2004) The relationship between psychopathic features, violence and treatment outcomes: the comparison of three youth measures of psychopathic features. Behavioural Sciences and the Law, 22, 85-102.

Zwi, M. \& York, A. (2004) Attention-deficit hyperactivity disorder in adults: validity unknown. Advances in Psychiatric Treatment, 10, 248-256.

\section{MCQs}

1 Which of the following best answer the question 'Is psychopathy the same as conduct disorder and antisocial personality?'

a yes

b no

c it overlaps with antisocial personality

d it overlaps with conduct disorder

e not all conduct disorder and antisocial personality disorders meet the criteria for psychopathy.
2 Regarding measures of psychopathy for those under 18 years old

a there are no available measures of psychopathy for those under 18 years old

b there are several self-report, informant-rated and interview measures for those under 18 years old

c current instruments provide well-validated cut-off scores for making a prototypical diagnosis

$d$ the instruments for those under 13 years old are based on either self-report or informant-rated measures

e the only current interview schedule is for those aged 13-18 years.

3 Which of the following measures have been independently validated in a variety of international settings and groups?

a the Psychopathy Checklist - Youth Version

b the Youth Psychopathic Traits Inventory

c the Child Psychopathy Scale

$\mathrm{d}$ all of the above

e none of the above.

4 Psychopathy in childhood and adolescence is associated with:

a earlier onset of antisocial behaviour

b more criminal convictions

c more violent offences

d substance misuse

e potentially poorer response to treatment.

5 Psychopathy in childhood and adolescence is:

a well recognised and a stable diagnosis across age ranges and from childhood to adulthood

b potentially useful in subtyping those who may be at high risk and need specialist interventions

c associated with neurocognitive (empathy and impulse control) deficits similar to those seen in adults with this disorder

$\mathrm{d}$ routinely assessed and used in sentence planning by the criminal justice system

e a potentially stigmatising label for a child or adolescent. 